Bolm Inst. oceanogr., S Paulo, 39(2):167, 1991

\title{
AGRADECIMENTOS AO CORPO CONSULTIVO
}

Os membros da Comissão Editorial do Instituto Oceanográfico da Universidade de São Paulo agradecem aos especialistas que contribuíram com suas revisões cuidadosas e sugestões valiosas para a qualidade dos trabalhos publicados no volume 39 do Boletim do Instituto Oceanográfico.

A todos os colegas do Corpo Consultivo: Tagea K. S. Björnberg, Frederico Pereira Brandini, Raimundo N. Damasceno, Aerovaldo Dell'Acqua, Liliana Forneris, Virgínia T. Garcia, Miryam B. B. Kutner, Antonio Miguel, Maria da Glória B. Soares Moreira, Denise Navas-Pereira, Edmundo Ferraz Nonato, Eurico Cabral de Oliveira Filho, José Zanon de Oliveira Passavante, Luiz Roberto de Moraes Pitombo, Joseph Ramus, Carlos Falavinha da Rocha, Roberto Sassi, Armando Augusto Henriques Vieira e Yoko Wakabara, por suas colaboraçōes graciosas nessa tarefa confidencial, nossos mais sinceros agradecimentos.

Yara Schaeffer-Novelli

Comissão Editorial

Presidente 